DOI 10.37882/2223-2982.2021.09.19

\title{
АНАЛИЗ ВАРИАТИВНОСТИ ЯЗЫКА СЕТИ С ТОЧКИ ЗРЕНИЯ СОЦИОЛИНГВИСТИКИ
}

\section{ANALYSIS OF THE VARIABILITY OF THE NETWORK LANGUAGE FROM THE POINT OF VIEW OF SOCIOLINGUISTICS}

Miao Qingqing

Summary: The rapid development of the Internet has created a new network culture that has a significant impact on the lives and worldview of people. A large number of network users communicate in this virtual space, and over time, the language of the network appears. Regardless of how users feel about the language, this new form of language has begun to gain attention. The network, or virtual communication space, distinguishes network communication from everyday communication. Participants in the communication act, communication experience, topics and communication goals differ, which is one of the main reasons for the variation in the language of the network. The article is devoted to the social aspect of the language. From a scientific point of view, this article analyzes the language of the network. The article includes a short introduction, key points and conclusion. The introduction examines the background of research, research methods, meaning, and a brief overview of the study of sociolinguistics and linguistic variation. The main part reveals the origin, the reason for the formation, the development trend and the current state of the network language. Further, the network language is considered from the point of view of sociolinguistics, phonetics, vocabulary and grammar, the forms and characteristics of variations of the network language are analyzed. Then the negative impact of the network language is considered, the concept of standardization is put forward, urging people to standardize and develop the network language, conclusions are drawn.

Keywords: sociolinguistics, network language, language variation.

\author{
Мяо Цинцин \\ Преподаватель, Северо-западный педагогический \\ университет, Ланьчжоу, Китай \\ Christine6771@126.com
}

Аннотация: Быстрое развитие Интернета создало новую сетевую культуру, которая оказывает значительное влияние на жизнь и мировоззрение людей. В этом виртуальном пространстве общается большое количество пользователей сети, со временем появляется язык сети. Независимо от отношения пользователей к этому языку, эта новая форма языка начала привлекать внимание. Сеть, или виртуальное коммуникационное пространство, отличает сетевое общение от повседневного. Участники коммуникативного акта, коммуникативный опыт, темы и коммуникативные цели различаются, что является одной из основных причин вариации языка сети. Статья посвящена социальному аспекту языка. С точки зрения науки, в этой статье проводится анализ языка сети. Статья включает краткое введение, основные положения и заключение. Во введении рассматриваются предпосылки исследования, методы исследования, значение и краткий обзор исследования социолингвистики и языковых вариаций. Основная часть раскрывает происхождение, причину образования, тенденцию развития и текущее состояние языка сети. Далее рассматривается сетевой язык с точки зрения социолингвистики, фонетики, лексики и грамматики, анализируются формы и характеристики вариаций сетевого языка. Затем рассматривается негативное влияние языка сети, выдвигается концепция стандартизации, призывающая людей стандартизировать и развивать язык сети, делаются выводы.

Ключевые слова: социолингвистика, язык сети, языковая вариация.

изучении обозначений и написания слов, коммуникационных процессов, культуры. Развитие сетевого языка является актуальным лингвистическим вопросом. С точки зрения социолингвистики, в этой статье описаны формы языковых вариаций языка сети, проанализированы причины его формирования с целью его стандартизации в перспективе.

Таким образом, из-за постоянного обновления и развития языка сети, важно вовремя изучить данный языковой феномен. Изучение сетевых ключевых слов, с точки зрения социолингвистики, может расширить горизонт исследования языка сети, способствовать всестороннему, систематическому изучению, а также проверить и дополнить социолингвистические теории. Основываясь на данных уже существующих исследований, эта статья 
дополняет изучение кибер-языка с точки зрения социолингвистики. Научная новизна заключается в обогащении знаний о кибер-языке, выдвижении мнений и предложений по его стандартизации и стремлении сделать более фундаментальное и систематическое изложение конкретной ситуации развития и изменения кибер-языка с использованием соответствующих теорий социолингвистики.

\section{Материалы и методы}

В статье собраны языковые данные с помощью Wechat, Sina-Weibo, Tik Tok, Baidu, а также проанализированы актуальные литературные источники. В работе выявляется и обобщается закономерность собранных данных. Используются такие методы как контент-анализ, статистический анализ, анкетный опрос, сравнительный анализ для детального изучения вариаций языка сети, включая грамматику, фонетику, лексику и прагматику.

\section{Обзор литературы}

Социолингвистика - это передовая наука, появившаяся в США в 1960-х гг. Она изучает социальную природу языка и различия дисциплин с точки зрения социальных наук с использованием теорий и методов лингвистики и социологии. С углублением науки и пониманием лингвистами языковой неоднородности, социолингвистика превратилась в межкультурное общение, коммуникативную социолингвистику, лингвистическую социализацию и овладение языком, анализ разговоров и исследование языковых вариаций, среди которых изучение языковых вариаций - это основное направление социолингвистики. С момента возникновения социолингвистики в 1960-х годах, лингвистические вариации, которые ранее игнорировались в лингвистике, привлекли повышенное внимание и стали основным объектом исследования социолингвистики [1].

Одним из представителей этого направления является «вариативная» школа американского социолингвиста У. Лабова [2]. Он выдвинул теорию «упорядоченной неоднородности». Взяв в качестве объекта исследования языковые вариации, У. Лабов разработал набор методов изучения языковых сообществ, сбора языковых материалов и проведения количественного анализа. Исследователь выступал за внедрение языка в общество и против теории Соссюра «изучения языка на основе языка», основанной на различии между языком и речью.

«Когда мы изучаем социальный аспект языка, нам всего лишь нужно наблюдать за человеком, а в то время, когда мы изучаем индивидуальный аспект языка, нам нужно наблюдать его из социальной среды» [3]. Это привело к значительным изменениям в направлении языковых исследований со времен Соссюра. Языковые исследования больше не ограничиваются внутренней лингвистической системой, они основываются на социальных факторах, чтобы изучить, как эти факторы влияют на функционирование и эволюцию языка, изучить языковые вариации и установить набор отличительных социолингвистических теорий и методов. Существует 3 идеи анализа и практики при работе с социальным значением в социальных языковых вариациях. Первая волна вариативных исследований связывает лингвистические показатели с макросоциологией: социально-экономическим классом, полом, расой и возрастом. Вторая волна использует этнографические методы для изучения влияния места жительства или региона на язык. В этих двух идеях вариация рассматривается как признак социальной классификации. П. Эккерт выдвинул теоретическую основу, согласно которой вариации составляют мощную социальную систему символов, потенциально выражающую все социальные проблемы в данном сообществе, и отражают социальную значимость, а также представляют собой силу для социальных изменений [4].

Необходимо отличать понятия «социолингвистика» и «лингвистическая вариативность». Социолингвистика - «это одна из важных ветвей лингвистики, это изучение отношений между языком и обществом» [5]. Основные аспекты социолингвистических исследований включают: языковые группы, языковые варианты, региональные и социальные варианты, отношения между языком и культурой и т.д. Социолингвистика также изучает влияние социальной природы и различий на язык, таких как этническая принадлежность, религия, социальный статус, пол, образование, возраст и т.д., и то, как языковые различия могут использоваться для определения социального статуса человека. В рамках данной статьи рассматриваются следующие концепции: языковые варианты, языковые вариации и переключение языковых кодов.

Языковые варианты относятся к различным формам, в которых язык отличается в системе и организации. Язык сети относится к системе языковых вариаций для удовлетворения коммуникативных потребностей некоторых пользователей языка. Наиболее распространенными языковыми вариантами являются варианты сообщества, региональные варианты, стилистические варианты и т.д.

Языковые вариации относятся к различиям в языке из-за социальных факторов, включая не только различия в синхронном распределении конкретного языкового элемента, но также и изменения языкового элемента в диахроническом процессе.

\section{Обзор языка сети}

Происхождение языка неразрывно связано с влияни- 
ем общества. Общество определяет язык, язык отражает и влияет на общество. Благодаря удобному, быстрому и широкому распространению информации, сеть постепенно превратилась в главную платформу, на которой люди выражают свое мнение и чувства в повседневной жизни. В сети регулярно увеличивается количество социальных дискуссий о социальных событиях и явлениях. Для удовлетворения потребностей общения рождаются новые Интернет-слова и выражения, например, «Не будьте слишком CNN-ным». Выражение произошло в 2008 году, когда в г. Лхасе были совершены разгромы, грабежи, пожоги. CNN вырезало из репортажей изображение нескольких бандитов, которые нападают на проезжающие мимо военные машины, намеренно скрывая насилие и цвет кожи нападавших. Серьезно искаженные факты спровоцировали собрание Всемирного китайского конгресса, который попросил CNN извиниться. В ответ на это ведущий новостей CNN Кафферти сделал оскорбительное замечание во время эстафеты Олимпийского огня в Пекине в США, назвав китайцев «группой дураков и бандитов, которые не изменились за 50 лет». В результате пользователи сети запустили популярную фразу «Не будьте слишком CNN-ным», выражая свое недовольство ложными сообщениями западных СМИ. Новое слово 'CNN' относится к умышленному искажению, односторонности, вырыванию из контекста и даже подделке фактов для того, чтобы скрыть чью-то грязную цель.

Из этого следует, что сетевые слова созданы общественностью на основе консенсуса, широко признанного, популярного. Большинство таких слов возникает в результате обсуждения горячих новостей и социальных явлений в режиме реального времени. На обсуждение представлены не только развлечения и повседневная жизнь, но и дипломатические и политические события.

\section{Анализы причин возникновения языка сети}

С развитием современной науки и технологий наступление сетевой эры предоставляет нам материальный носитель для создания сетевого языка. Согласно 43-му статистическому отчету о развитии Интернета в Китае, опубликованному Китайским информационным центром Интернета, по состоянию на декабрь 2018 г. количество пользователей Интернета в Китае достигло 829 млн, а показатель распространения достиг 59,6\%, что на 3,8 процента выше, чем в конце 2017 г., за год появилось 56,53 млн новых пользователей Интернета. Масштаб мобильных пользователей сети в Китае составляет 817 млн, а доля пользователей Интернета, выходящих в Интернет через мобильные телефоны, достигает 98,6\%. Показатель распространения Интернета приближается к 60\%, повысилась его доступность. Благодаря удобству и виртуальности сетевого оператора, для общественности обеспечивается свободная и толерантная языковая среда. Сетевой язык богаче и выразительнее традици- онного. Таким образом, постоянное развитие сетевой платформы сети Интернет способствует широкому распространению и использованию языка сети.

«Язык - это социальное явление. Язык возникает с формированием человеческого общества и развивается с изменениями общества» [6]. Развитие социальной политики и экономики вызвало языковой контакт. Влияние иностранной культуры, переплетение разных идей и появление нового будут вызывать языковые изменения. 2018 год знаменовал собой начало реализации духа XIX Национального съезда партии и 40-ую годовщину реформ. После реформ в КНР часто происходили культурные обмены с другими странами, возникали новые идеи, предоставляя материал для создания инноваций. В толерантной социальной среде люди осмеливаются вводить новшества и обращать внимание общества на свою личность. Культурный обмен между регионами также стал удобнее, поэтому пользователи сети могут цитировать различные местные диалекты и пословицы.

Сетевое общение - это письменная форма выражения, у которой тоже есть свои недостатки. По сравнению с повседневным общением ему не хватает потенциальных средств общения, таких как голос, выражение лица и язык тела. В некоторой степени это влияет на точность и эмоциональность языкового выражения. Некоторые диалекты или разговорные выражения не имеют соответствующих слов или предложений. Чтобы исправить этот недостаток и передать информацию полнее и точнее, пользователи сети задействовали свое воображение, креативность, и, сознательно или бессознательно, создали богатый и интересный сетевой язык на основе своего родного языка, чтобы избежать двусмысленности или неправильного понимания неуместных слов.

Сетевой язык удовлетворяет психологические потребности молодых людей в самовыражении и стремлении следовать моде, а также отражает психическое и жизненное состояние современных людей. Несмотря на то, что сетевое общение очень удобно, оно все же не может удовлетворить потребности современных людей с точки зрения языкового выражения, поэтому сетевой язык появляется по мере необходимости. Интернет-пользователи в Китае - это в основном группы молодежи и среднего возраста, и постепенно ими становятся пожилые люди. Согласно 43-му статистическому отчету о развитии Интернета в Китае, по состоянию на декабрь 2018 г. возрастная группа 10-39 лет составляла $67,8 \%$ от общего числа пользователей сети, из которых возрастная группа 20-29 лет составляла наибольшую долю - 26,8\%. Группа людей среднего возраста в возрасте 40-49 лет составляла 15,6\%, а доля пользователей сети в возрасте 50 лет и старше составляла 12,5\%. Результаты представлены в Таблице 1. 
Таблица 1

Возрастное распределение пользователей сети Интернет в КНР

\begin{tabular}{|c|c|c|c|c|c|c|c|}
\hline Возраст (лет) & 10 & $10-19$ & $20-29$ & $30-39$ & $40-49$ & $50-59$ & 60 и более \\
\hline$\%$ & $4,1 \%$ & $17,5 \%$ & $26,8 \%$ & $23,5 \%$ & $15,6 \%$ & $5,9 \%$ & $6,6 \%$ \\
\hline
\end{tabular}

Источник: Информационный чентр китайской сети Интернет «Статистическое исследование развития Интернета в Китае»

Таблица 2

Распределение пользователей сети Интернет в КНР по уровню образования

\begin{tabular}{|c|c|c|c|c|c|}
\hline Уровень образования & Начальная школа & Средняя школа & Старшая школа & Среднее образование & Высшее образование \\
\hline$\%$ & $18,2 \%$ & $38,7 \%$ & $24,5 \%$ & $8,7 \%$ & $9,9 \%$ \\
\hline
\end{tabular}

Статистические данные показывают, что большинство китайских пользователей сети имеют среднее образование. Распределение пользователей сети Интернет в КНР по уровню образования представлено в Таблице 2.

Из приведенных ниже данных видно, что основная группа пользователей сети - это люди молодого и среднего возраста, социальная среда, в которой они живут, обеспечивает им постоянно развивающуюся и улучшающуюся сетевую среду. Пользователи сети этого возраста получили среднее образование и имеют определенную языковую базу. Люди в этом возрасте более восприимчивы к новому, особенно студенты, которые могут свободно бунтовать и не желают быть связанными традициями. Поэтому они будут спонтанно менять слова и предложения в соответствии со своими собственными мыслями и чувствами, чтобы языковое выражение больше соответствовало их личности и образу мышления. Использование сети имеет тенденцию распространяться и среди пожилых людей, потому что развитие смартфонов сделало нашу жизнь повсюду окруженной сетью, развитие общества и темп жизни ускорились. Это заставляет людей среднего и пожилого возраста также получать новую информацию из сети, поэтому понимание языка сети становится необходимым выбором.

С социолингвистической точки зрения здоровое плюралистическое общество должно допускать существование многоязыковых сообществ, и для сетевых групп нормально иметь свои собственные языковые привычки [7]. Ранее язык сети применялся только в сети, но с постоянным расширением круга пользователей и совершенствованием Интернет-технологий, сетевой язык стал основным носителем, с помощью которого люди могут собирать, публиковать информацию и обмениваться ею в сети. Использование сетевого языка набирает популярность, его охват и влияние растут. Сегодняшний сетевой язык больше не ограничивается виртуальным пространством сети, он проникает в телевидение, газеты и другие основные средства массовой информации и используется многими людьми в повсед- невном общении, особенно молодыми группами.

Согласно результатам опроса, 38,46\% респондентов считают, что они не будут использовать модные интернет-слова в официальных случаях. Причина заключалась в том, что интернет-слова нарушили бы формальность событий, а использование таких слов сделало бы поведение нерегулярным и неформальным. Но 26,5\% верят, что они будут использовать интернет-слова в официальных случаях, а 35,04\% полагают, что они будут использовать их в соответствии с реальной ситуацией. Причина в том, что интернет-слова могут показать ученых как интересных, юморных и близких к публике людей, а скучных ученых с ними будет легче понять (Zhang, 2019). Из приведенных данных видно, что многие люди даже в официальных случаях будут использовать язык Интернета в зависимости от ситуации.

У сети две характеристики: одна связана с молодостью, другая - с культурой. Молодые люди активны и гибки в мышлении, любят новые вещи, стремятся общаться, пропагандируют инновации, следят за модой и не желают слишком много ограничений в реальной жизни (включая ограничения основных языковых норм). Анонимный виртуальный мир Интернета дает молодым людям возможность проявить себя. В то же время, из-за их высокого культурного уровня и знакомства с английским и компьютерным языком, появление «интернетсловечек» неизбежно. Язык - это отражение времени. В определенной степени язык сети является отражением нынешней «сетевой эпохи», которая тесно связана с образом жизни и мышлением современных людей. Таким образом, мы можем сделать вывод, что сетевой язык будет использоваться не только в повседневной жизни, но и в рамках официального общения.

На данный момент существенно снижен порог для входа жителей в сеть, а эффективность обмена информацией - повышена. Интернет-развлечения развиваются по пути стандартизованного развития: коэффициент пользователей, просматривающих короткие видео, со- 
ставляет почти 80\% (Информационный центр китайской сети Интернет, 2019). Таким образом, быстрое развитие Интернета расширило сферу действия и влияние сетевого языка.

\section{Язык сети с точки зрения сошиолингвистики}

Язык сети - это разновидность языковой вариации, вызванная и постепенно сформированная общественным развитием, научно-техническим прогрессом и популяризацией сети. Это результат изменения современного китайского языка в особом коммуникативном контексте сети. В виртуальном сообществе Интернета язык отправителя - это языковой элемент с аналогичным распределением, то есть язык - это языковой код со схожими характеристиками, такими как словарный запас, синтаксис и дискурс. Сетевой язык - это основной инструмент интернет-общения. Чтобы адаптироваться к контексту, язык сети также изменился соответствующим образом [8].

Теперь рассмотрим вариативность языка сети и его характеристики. Начнем с ономатопеи или звукоподражания. Люди не слышат голоса и тона друг друга в интернет-чате, но звукоподражательные ответы могут передавать голос людей. Они похожи на традиционные звукоподражания, но имеют более избыточные формы выражения, такие как буквы, символы, числа и т.д. Эти формы выражения имеют больше преимуществ при выражении эмоций, значительно расширяя пространство воображения обеих сторон чата, поэтому пользователи сети предпочитают их.

\begin{tabular}{|l|l|}
\hline Skr & $\begin{array}{l}\text { Это слово изначально использовалось для описания звука } \\
\text { автомобильных тормозов или трения шин о землю. Его также } \\
\text { можно использовать в качестве поддержки и похвалы в не- } \\
\text { которых ситуациях, чтобы люди знали, что они правы. }\end{array}$ \\
\hline HeHе & $\begin{array}{l}\text { Его используют для выражения насмешки, беспомощности и } \\
\text { немного ироничного тона. }\end{array}$ \\
\hline mua & Имитирует звук поцелуя \\
\hline Kiss & Имитирует звук поцелуя \\
\hline PIA & Звук пощечины \\
\hline KКК & Имитирует смех и кашель \\
\hline
\end{tabular}

Следующая форма - омофоны. Феномен омофонов является частым фонетическим изменением в развитии и вариации сетевого языка. Его можно разделить на пять категорий: английский омофон, диалектный омофон, цифровой омофон, китайский омофон и алфавитный, цифровой и китайский омофон. Под омофономи понимается фонетическая двусмысленность, то есть ими обозначаются слова и выражения, которые имеют единый смысл, но при этом пишутся поразному.
Различают также цифровые омофоны, они относятся к языковым единицам, используемым в Интернете для выражения определенных концепций или значений с помощью одной или группы арабских цифр. С помощью оригинальной фонетической формы чисел воспроизводятся некоторые звуки других языков, таких как китайский, в соответствии с принципом омонимии и близости, и выражается значение, представленное гармоническими тонами языка.

\begin{tabular}{|l|l|}
\hline 520 & Я тебя люблю \\
\hline 9494 & Так сказать (就是就是) \\
\hline 1314 & Целая жизнь (一生一世) \\
\hline
\end{tabular}

Диалектный омофон относится к диалектным словам из-за своей неповторимой выразительности. Например, в сетевом языке в южных диалектах $\mathrm{n}$ и I неразличимы, получаются сетевые термины, такие как'Lanshouxianggu' (蓝瘦香菇），'Guliang'（菇凉）。

\begin{tabular}{|c|l|}
\hline $\begin{array}{c}\text { Lanshouxianggu } \\
\text { (蓝瘦香菇) }\end{array}$ & Печаль, хочу плакать \\
\hline $\begin{array}{c}\text { Housailei } \\
\text { (猴赛雷) }\end{array}$ & $\begin{array}{c}\text { Это омоним на кантонском диалекте, который } \\
\text { значит «крутая, классная». }\end{array}$ \\
\hline $\begin{array}{c}\text { Fakaixin } \\
\text { (伐开心) }\end{array}$ & Несчастный, шанхайский диалект \\
\hline 你四不四俊 & Ты тупой? \\
\hline 滚犊子 & Отвали, северо-восточный диалект \\
\hline
\end{tabular}

Далее рассмотрим лексические вариации. Первая - усечение. Частым источником сокращений в кибер-языке является замена буквенных сокращений английскими инициалами, числами или китайским пиньинь.

\begin{tabular}{|c|c|}
\hline $\begin{array}{c}\text { Awsl } \\
\text { (啊我死了) }\end{array}$ & $\begin{array}{l}\text { Это аббревиатура от «умираю от умиления», которая } \\
\text { используется для описания волнения от просмотра } \\
\text { милых, многообещающих вещей и т.д. }\end{array}$ \\
\hline $\begin{array}{c}\text { 注孤生 (注定 } \\
\text { 孤独一生) }\end{array}$ & $\begin{array}{l}\text { Обреченный на одинокую жизнь. Из книги «Сто лет } \\
\text { одиночества». Это выражение описывает человека, } \\
\text { не понимающего девушек. Теперь это распространя- } \\
\text { ется и на самоуверенных девушек, не флиртующих } \\
\text { с мужчинами, поскольку они убеждены, что им во- } \\
\text { обще не нужен мужчина. }\end{array}$ \\
\hline 人艰不拆 & Жизнь и так сложна, не стоит прояснять \\
\hline LOL & Смеяться в голос \\
\hline
\end{tabular}

Вторая лексическая вариация - преобразование части речи. Это эффективный способ словообразования, особенно в сетевом языке. Основные его проявления: 
(1) Существительные используются как глагол

\begin{tabular}{|l|l|}
\hline 我班去了 (我上班去了) & Я ушел на работу. \\
\hline 你雅虎了吗(你上网了吗) & Ты онлайн? \\
\hline 我电话呢 (我在打电话呢) & Я на телефоне. \\
\hline 百度一下 & Поищи в Ваidи \\
\hline
\end{tabular}

(2) Существительные используются как прилагательные

\begin{tabular}{|c|c|}
\hline 皮一下很开心 & $\begin{array}{l}\text { «Пи» изначально было существи- } \\
\text { тельным. «Пи» здесь означает } \\
\text { положительные эмоции непо- } \\
\text { слушный, и обычно означает, } \\
\text { выражение используется, чтобы } \\
\text { сказать «я очень счатлив» }\end{array}$ \\
\hline 讲话非常克且鱼 & $\begin{array}{l}\text { «Речь была очень похожа на речь } \\
\text { Клинтона», что означает, что че- } \\
\text { ловек врет }\end{array}$ \\
\hline 很男人 (很有男人味) & Это очень по-мужски. \\
\hline 太墓了(水平太低了) & Уровень слишком низкий. \\
\hline
\end{tabular}

Следующая вариация - синтаксические изменения, то есть изменение порядка слов в предложении. Такие предложения обычно создаются пользователями сети для забавы или по причине недостаточного образования, некоторые предложения заимствуются из диалектов, некоторые - из фильмов Гонконга и Тайваня. В гуандунской речи есть особый тип предложения, состоящий из глагола и послелога. Например, «проходите» (你走 先), «дайте побольше» (给多几个), «я сначала поем» ( 我吃饭先), сегодня скучно говорить (今天很无聊的说) (В предложении '的说' не имеет практического значения и является модальной частицей).

\section{Рассмотрим характеристики языка сети:}

\section{1. Своевременность.}

Сетевые слова актуальны, они появляются в результате публичного обсуждения горячих новостей и социальных явлений в режиме реального времени. Общество постоянно развивается и меняется, и постоянно появляются новые вещи. С течением времени люди перестают обращать внимание на событие, накал события уменьшается, а модные слова, сопровождающие это событие, постепенно исчезают. Например, популярное слово «фристайл», которое происходит от феномена погони за звездами, обычно относится к импровизационной и случайной игре. В хип-хоп рэпе «фристайл» означает импровизационный рэп. Причина его популярности в том, что люди могут узнать об иностранной музыкальной культуре через Интернет и улучшить свое восприятие различных видов искусства. Вторая причина заключается в том, что это первая разновидность рэпа в Китае, которая очень нова для публики. ВНо с окончанием программы слово больше не упоминается. Также, как «скр», «давать силу» (给力), «божественный конь плывет по облакам» (神马都是浮云) и т.д. Такие слова могут выражать эмоции и мысли людей, а новые, соответствующие общественному вкусу, заменяют старые. Следовательно, жизнь сетевого языка ограничена и имеет своевременный характер.

\section{2. Подверженность влиянию иностранных языков}

Язык сети - это конкретное выражение языкового контакта. Языковой контакт относится к языковым контактным отношениям, вызванным контактом между разными национальностями и сообществами из-за взаимного контакта в социальной жизни. Ни один язык в мире не существует изолированно и всегда имеет различную степень контакта с другими языками [9]. Обмен различными культурами приводит к изменениям в структуре или морфологии языка, как и в китайском. «При смешивании кода компонент кода А в некоторой степени включается в другой - код Б. Код Б обычно является доминирующим, в то время как код А является дополнительным, и он не используется сознательно, как код Б» [10].

С точки зрения феномена смешения кода в социолингвистике, в сетевых словах есть много смешанных китайско-английских, таких как 'you are out' (你 out 了) и ' $x$ ing' (启动 ing, 做作业 ing 等等)，'为 $\times x$ (疯狂) 打 call'. 'Out' означает выезд откуда-то в другой город, поселок и т.д. В '你 out 了' появилась новая идея, которая устарела. Чтобы достичь наилучшего выразительного эффекта в предложении произошло переключение между английским и китайским языками, которое направлено на преобразование двух языков в соответствии с потребностями прагматической среды. «X-ing» добавляет «ing» после глагола, чтобы указать на конструкцию длительного момента. Форма «X-ing» имеет свои уникальные особенности: с одной стороны, введение английских морфем в китайский язык может дать людям ощущение новизны как в слуховом, так и в зрительном смысле. С другой стороны, писать и печатать быстро и удобно.

\section{Стандартизашия языка сети}

Хао Минцзянь, главный редактор Bian Wen Chew Zi, считает, что китайский язык переживает кризис безрассудства, непонятности, пошлости и игривости. Среди всех факторов наиболее важным является неправильное использование сетевого языка. Путаница в использовании китайского языка соответствует стремительности жизнедеятельности нашего времени. Сетевой язык оказывает большое влияние на стандартизацию китайского языка, что не способствует развитию китайского языка. Язык сети основан на традиционном языке, который используется в сетевой среде. Они имеют сходство с 
традиционным языком, но в то же время есть огромные различия. Однако альтернативное выражение в сетевом языке - это подрыв традиционных языковых норм, и его влияние нельзя игнорировать.

Необходимо рассмотреть грамматические вариации языка. В грамматике английского языка суффиксы играют очень важную роль. Например, 'going on the way', что означает нахождение в дороге, длительное время. Пользователи сети часто стремятся к простоте и удобству сетевого языка. Некоторые также добавляют 'ing' для удобства на китайском языке. Например, «сегодня снова идет дождь, мероприятия на свежем воздухе надо отменить, угнетает-ing» (выражает настроение «сейчас очень подавлен»). После дождя и солнечной погоды они скажут: «Ха-ха, после дождя мероприятия будут проходить как обычно, счастлив-ing» (выражая настроение в настоящее время). Эти предложения совершенно нерегулярны, что заставляет людей чувствовать себя странно и серьезно влияет на целостность языка.

В сетевом языке многие преобразованные слова стали модными выражениями, например, “牛的内脸”, что дословно переводится как «внутреннее лицо коровы». Большинство пользователей сети знают, что значение этого выражения - «слезы на лице», но тех, кто не часто использует сетевой язык, такое выражение может привести к недопониманию. В настоящее время многие программы для набора текста в Интернете будут иметь функцию омофонического подбора неправильно набранных слов, что в определенной степени создает условия для ввода людьми неправильных слов. Со временем у многих людей в связи с этим появятся когнитивные отклонения.

Важно учитывать, что синтаксическая аномия снижает способность читать и выражаться. Цель общения в социальных сетях такая же, как и в повседневной жизни, обмен информацией при письме может не только показать умение выражаться у отправителя, но также проверить способность получателя читать и понимать информацию. Следовательно, в процессе обмена информацией в Интернете необходимо разобрать синтаксическое выражение языка и текста, чтобы добиться дальнейшего улучшения от устного выражения к письменному. Например, популярный в сети смешанный китайско-английский синтаксис, такой как «есть» и «спать» в настоящем длительном времени. Большинство людей могут понять, что другая сторона выражает длительность действия, но для пользователей сети, которые не знают английского языка, такой нестандартный синтаксис языка может вызвать препятствия для понимания прочитанного. Кроме того, существует множество явлений синтаксической аномии, таких как инверсия субъекта, предиката и объекта, например, как в выражениях «съешь меня» и «почему ты». Чтобы общаться было удобно, люди выражают информацию сразу, не задумываясь. В конечном итоге, эти инверсии повлияют на суждения учащихся о языковом строении и на их способности к чтению и выражению.

Стандартизация сетевого языка требует изменения действующих норм закона. Мы должны улучшить законодательные нормы Интернета, в основном принять технические и процедурные нормы, координировать и сотрудничать с соответствующими предприятиями, а также полностью задействовать роль сетевой медиаплатформы для содействия стандартизации сетевого языка. Укрепляя стандартизацию правовой конструкции, пользователи сети могут обращать внимание на свои слова и поступки при общении, а также могут выполнять свои соответствующие обязанности и обязательства, пользуясь свободой слова.

Основная проблема сетевого языка заключается в том, что язык, используемый пользователями сети в среде с ненастоящими именами, особенно в чатах и форумах, слишком вульгарен и нецивилизован. В частности, использование онлайн-имен имеет тенденцию быть насильственным и порнографическим; в процессе разговора в Китае чаще встречаются оскорбления и клевета; высказываемые мнения являются негативными и неприличными. Невозможно полностью и эффективно очистить сетевую «экологию» с ограничениями правовой системы. Следовательно, воспитание добродетелей необходимо укреплять в жизни и в сети, чтобы постоянно улучшать личные моральные качества пользователей сети и очищать сетевую среду. В социальной среде мы должны создать атмосферу любви к себе и самодисциплины. Мы не должны использовать открытость и бессмыслицу ненастоящих имен, чтобы быть цивилизованными пользователями сети и говорить на цивилизованном сетевом языке.

Также очевидна необходимость укрепления норм языкового выражения в школьном обучении. Из-за популярности смартфонов, у учеников младших и старших классов и даже у некоторых учеников начальной школы есть мобильные телефоны. Ученики изучают новые сетевые термины в процессе онлайн-общения, которые будут использоваться не только в повседневном общении, но и в письменной форме. Подростковый возраст это чувствительный период для детей, когда они только учатся выражаться с помощью языка, а когнитивные способности у них еще не развиты, поэтому сеть легко может повлиять на них. Это требует от школьных учителей соблюдения нормативных требований к преподаванию и передачи точного и стандартизированного языка, чтобы противостоять влиянию языка сети. 


\section{Зак^ючение}

Сетевой язык, как способ общения в языковом сообществе, постепенно привлекает внимание людей из всех слоев общества. Между кибер-языком и традиционным языком есть большие различия. Разница заключается не только в скорости и широте распространения информации, но и в способе мышления, кибер-язык влияет на понимание мира людьми. Традиционный язык - это своего рода социализированный язык, который должен отражать единое понимание нации, культуры, ценностей и убеждений в реальном мире, он несет в себе историю. Сетевой язык подчеркивает индивидуальность.

С точки зрения причин, сетевой язык -продукт времени, появившийся при условии политической демократии, экономического процветания и беспрецедентно активного культурного обмена в Китае. С появлением новых вещей и идей и широким применением компьютеров, пользователи сети готовы и осмеливаются творить, способствуют творчеству и улучшают качество культуры людей. Язык сети адаптируется к быстро меняющейся современной жизни, а также компенсирует недостатки самого сетевого общения. Следовательно, сетевой язык - это продукт адаптации к развитию времени, и он име- ет собственную ценность существования и развития. Как мы все знаем, у влияния сетевого языка есть две стороны. Одна сторона оказывает определенное негативное влияние на традиционный язык и сетевую экологическую среду. Например, отсутствие грамматических норм, вульгаризация сетевого языка, двусмысленность, вызванная сетевыми словами, и потеря синтаксических норм приводят к снижению способности читать и выражать свое мнение, «что оказывает определенное негативное влияние на традиционный китайский язык, особенно в отношении преподавания китайского. Например, ученики намеренно или даже самодовольно искажают свои первоначальные намерения или пишут неправильные символы в своих сочинениях и т.д. Однако мы наблюдаем не только отрицательную сторону, но и положительную роль. Сетевой язык не только обогащает современный китайский язык, делает его более выразительным, с заметным визуальным эффектом и разнообразными формами выражения, но также удовлетворяет потребности людей в раскрытии своей личности и адаптации к быстрому ритму современной жизни. Имея дело с сетевым языком, мы должны разделить его на две части, диалектически отнестись к нему, и изо всех сил постараться возвысить его сущность, отбросив минусы.

ЛИТЕРАТУРА

1. Tao Hongyin, Daming Xu, Tianwei Xie Contemporary Linguistics Theories Series . Pragmatics 1997, 7.3:428-429.

2. Trask, R.L. (1997). A Student's Dictionary of Language and Linguistics. London: Arnold. pp. 124. ISBN 0-340-65266-7.

3. P. Eckert, 2012, Three Waves of Variation Study: The Emergence of Meaning in the Study of Sociolinguistic Variation [J].Annual Review of Anthropology, (6) :87-100.

4. Revisiting Models and Theories of Language Standardization. (2021). In W. Ayres-Bennett \& J. Bellamy (Eds.), The Cambridge Handbook of Language Standardization (Cambridge Handbooks in Language and Linguistics, pp. 25-198). Cambridge: Cambridge University Press.

5. Katia Chirkova; Yuan Chen. Chen Yuan and Chinese sociolinguistics. Armonk, NY : M.E. Sharpe - 2004. - P. 96.

6. Mingjie Li and Zhou Ya, 2011. "Development trends of the author's writing sense from Song to Qing Dynasty in China”, Publishing Journal, No.3, pp.18-23.

7. Mingjie Li and Mingjuan, Li, "Knowledge Service Models of Digital Library in Distance Education Environment and Their Realization”, The 2nd International Conference on Information Technology in Education (El), 2009.

8. Hudson, R.A. 2000, Sociolinguistics [M]. Beijing: Foreign Language Teaching and Research Press.

9. ZHANG Weiyou. (2006). English Lexicology. Wuhan: Huazhong Normal University Press.

10. Mingjie Li etc., 2006. "Outlook of the Education of LIS: a Report from the Third International Symposium on LIS Education in the Digital Age", Document, Information and Knowledge, No.3, pp.5-9.

11. Edward Sapir: Language: An Introduction to the Study Speech[M]. Beijing: Foreign Language Teaching and Research Press, 2002.127.

(с) Мяо Цинцин (Christine6771@126.com).

Журнал «Современная наука: актуальные проблемы теории и практики» 